\title{
U⿱宀⿻三丨口
}

\section{Electrochemically driven reagent release from an electronic suture}

Morelli, F., Anderson, A., McLister, A., Fearon, J-J., \& Davis, J. (2017). Electrochemically driven reagent release from an electronic suture. Electrochemistry Communications, 81, 70-73.

https://doi.org/10.1016/j.elecom.2017.05.020

Link to publication record in Ulster University Research Portal

\section{Published in:}

Electrochemistry Communications

Publication Status:

Published (in print/issue): 01/08/2017

DOI:

10.1016/j.elecom.2017.05.020

\section{Document Version}

Author Accepted version

\section{General rights}

Copyright for the publications made accessible via Ulster University's Research Portal is retained by the author(s) and / or other copyright owners and it is a condition of accessing these publications that users recognise and abide by the legal requirements associated with these rights.

\section{Take down policy}

The Research Portal is Ulster University's institutional repository that provides access to Ulster's research outputs. Every effort has been made to ensure that content in the Research Portal does not infringe any person's rights, or applicable UK laws. If you discover content in the Research Portal that you believe breaches copyright or violates any law, please contact pure-support@ulster.ac.uk. 


\title{
Electrochemically driven reagent release from an electronic suture
}

\author{
Fionnuala Morelli, Ashleigh Anderson, Anna McLister, John-Joe Fearon and James Davis ${ }^{1 *}$ \\ School of Engineering, Ulster University, Jordanstown, \\ Northern Ireland, BT37 OQB
}

\begin{abstract}
Sutures loaded with growth factors or antimicrobials are common place but the release of the therapeutic agent is almost invariably achieved through passive release mechanisms. A gold microwire loaded with cellulose acetate phthalate encapsulated drug droplets is proposed as an alternative design approach. The release mechanism relies upon the imposition of a suitable reducing potential at the gold suture resulting in an increase in local $\mathrm{pH}$ and thereby induces the dissolution of the polymeric binder and releases the drug. The ability to actively control the dissolution-release processes could lay the foundations for smart suture design where more responsive/metered dosing can be achieved.
\end{abstract}

\section{Keywords}

Smart Suture; Wound Diagnostics; Electronic Textile; Drug Delivery

$\begin{array}{ll}\text { Main text } & 2141 \\ \text { Figure }(4 \times 200) & 800 \\ \text { Total } & 2941\end{array}$

References $\quad 639$

${ }^{1}$ To whom correspondence should be addressed. T: +44(0)28903 66407; E: james.davis@ulster.ac.uk 


\subsection{Introduction}

Sutures are an invaluable tool in the treatment of major wounds where they offer a speedy method of binding apposing tissues and, in principle, can facilitate wound healing[1-4]. While the general mechanism of wound closure has changed relatively little in recent years, the materials employed in the manufacture of sutures have evolved considerably. Biodegradability, physical structure and chemical composition are the key factors subject to manipulation and there is a wealth of commercially available variants [2,3]. Sutures possessing antimicrobial activity are now commonplace and have arisen partly in response to the long standing issues of surgical site infection (SSI)[3]. The latter are generally acknowledged as being the most commonly incurred postoperative complication and are attributed to $15-20 \%$ of all nosocomial infection arising after surgery $[5,6]$. It has been demonstrated that sutures loaded with antimicrobial agents (such as triclosan or silver nanoparticles) reduce infection rates and improve wound recovery[2,3,6-10]. Irrespective of design, commercial sutures are typically based on a thread-like form to provide the mechanical resilience needed to draw the wound edges together and, thereafter, the antimicrobial features are invariably delivered through passive interaction with the surrounding tissue[2]. Given the increasing concerns over antimicrobial resistance, there is a need for a further improvements in suture design where the latter is capable of providing a more active role - either through providing diagnostic telemetry of the healing dynamics or enabling the targeted delivery of drugs to the site of infection. The aim of the present communication is to evaluate the use of a gold-silver composite thread as a platform through which electronic sutures capable of controlling the release of a chemical agent could be developed.

Kim and Colleagues (2012) demonstrated a microfabricated strip sensor capable of sensory feedback and actuation and have heralded a step change in suture design[11]. The present investigation has similarly sought to explore the controlled actuation through a potentially simpler, though more versatile and easily implemented electrochemical route. The rationale revolves around the encapsulation of the model drug (Toluidine Blue O, TBO) within cellulose acetate phthalate (CAP) droplets which are dispersed along the length a gold micro wire (25-100 $\mu \mathrm{m}$ diameter) as indicated in Figure 1. The CAP polymer binder is $\mathrm{pH}$ sensitive and is extensively used in oral tablet formulations to enable delivery of drug to the intestine where the alkaline environment dissolves the protective coating[11-16]. Thus, it was envisaged that upon the imposition of a suitably reducing potential $(-1 \mathrm{~V}$ to $-2 \mathrm{~V})$ at the gold electrode, the local $\mathrm{pH}$ is increased and the CAP droplets should dissolve and thereby release the drug[17]. 
The wire itself lacks the necessary tensile strength to pull the wound surfaces together but can be incorporated as an additional component within a conventional suture thread. A commercial silver thread is employed as both the structural suture backbone and second electrode in the electrochemical design. This report examines the electrochemical behaviour of the various components and assesses the efficacy of the proposed mechanism.

\subsection{Experimental Details}

Electrochemical measurements were conducted using a $\mu$ Autolab computer controlled potentiostat (Eco-Chemie, Utrecht, The Netherlands). All measurements were conducted at $22^{\circ} \mathrm{C} \pm 2^{\circ} \mathrm{C}$ in Britton Robinson buffer ( $\mathrm{pH}$ 3-10) unless stated otherwise. Gold and Silver wires were supplied by Goodfellow Ltd. In cases where a three electrode configuration was employed, a silver/silver chloride half cell (3 $\mathrm{M} \mathrm{NaCl}, \mathrm{BAS}$ Technicol) served as the reference. Conductive silver thread $(0.4$ $\Omega / \mathrm{cm}$ ) was supplied by Kitronik Ltd (Nottingham UK). The thread is composed of 96 individual filaments, each coated with a micron-thick layer of silver. The fabrication process involves a primary twist comprising 16 filaments of cotton. Two primary twists are subsequently wound together to form the secondary twist and finally three of the latter are combined to yield the final thread consisting of 96 filaments and is approximately 18 denier. The Toluidine Blue $\mathrm{O}(5 \mathrm{wt} \%)$ was mixed with the CAP polymer through dissolution in acetonitrile and then dropped and spread along the length of the gold wire. While it was initially anticipated that application of the TBO/CAP mixture to the gold would have led to a coherent film, the polymer spontaneously coalesced into discrete droplets along the length of the wire as a consequence of surface poor wetting. This coating process was repeated up to 4 times to increase the yield of TBO. Electrochemical release was induced through holding the potential at $-1,-1.5,-1.75$ or $-2 \mathrm{~V}$ for a given period (typically $10 \mathrm{~s}$ ) and then recording the absorbance spectrum $(200-800 \mathrm{~nm})$ in a $1 \mathrm{~cm}^{3}$ volume cuvette.

\subsection{Results and Discussion}

The efficacy of employing cellulose acetate phthalate as the controlled release polymer was briefly assessed using gelatin as the simulated tissue matrix. Toluidine Blue $O$ was used as a model drug as its release could be readily monitored through visual inspection ( $\lambda \max =591 \mathrm{~nm}, \varepsilon=2.98 \times 10^{3} \mathrm{~L}^{-1}$ $\mathrm{mol} \mathrm{cm}^{-1}$ ) or, as detailed later, through uv-vis spectroscopy. The thread was initially washed to remove interfacial TBO such that only the dye encapsulated within the polymer matrix remained. The thread was then immersed in gelatin samples whose $\mathrm{pH}$ had been previously adjusted and left 
for up to 48 hours. The results of the study are highlighted in Figures $2 \mathrm{~A}->\mathrm{F}$ where it can be seen that the TBO only emerges when the $\mathrm{pH}$ is alkaline. Dissolution of the cap was found to be extremely slow from neutral or mildly alkaline $(\mathrm{pH} 8)$ with diffusion of the TBO into the surrounding gelatin observed after only 48 hours.

The CAP/TBO droplets positioned on the gold wire $(100 \mu \mathrm{m})$ are shown in Figure $2 \mathrm{G}$ though their relative positioning is exaggerated for clarity. The structure of the conductive thread is highlighted in Figure $2 \mathrm{H}$ and it can be seen that, while silver coats each of the individual fibres within the braid, there are sections where the underlying cotton is exposed. This is consistent with previous reports of electroless deposition of silver on fabrics and can be expected where the plating solution has failed to nucleate on particular areas or where the braiding has prevented sufficient penetration[18-20]. Nevertheless, the silver deposition clearly extends along the length of the thread and is sufficiently coherent to retain conductivity when twisted or sewn which is ideal for the proposed application. It should be noted that the prime rationale for the commercialisation of the thread was targeted at emerging 'e-fabric' and wearable electronics and designed specifically for sewn and woven applications. The ability of the thread to serve as a viable reference/counter electrode was assessed through comparing the potentiometric response to chloride ion whereby a Nernstian response (-59 $\mathrm{mV}$ ) was obtained The tensile strength of the conductive thread was investigated and found to be 1.6 $\mathrm{N} /$ Tex (\%RSD $=9.1 ; \mathrm{N}=6$ ) which compared well with conventional Vicry ${ }^{\circledR}$ braided suture $(0.57$ N/Tex) [21]. Thus it could be expected that the electronic thread would provide the necessary strength to draw the apposing wound surfaces together and enable closure.

A cyclic voltammogram detailing the response of a gold microwire (50 $\mu \mathrm{m}$ diameter) towards ferrocyanide ( $2 \mathrm{mM}, 0.1 \mathrm{M} \mathrm{KCl}$ ) using a conventional three electrode system with a $3 \mathrm{M} \mathrm{NaCl}$ half cell and platinum counter electrode is detailed in Figure 3 . The voltammetric response produces a sigmoidal profile characteristic of microelectrode behaviour as anticipated given the small dimensions of the gold wire. Upon switching the cell configuration to a two electrode system in which the silver thread is employed as both reference and counter electrode, the voltammetric profile was found to retain the same shape but has shifted to less positive potentials. The latter can be attributed to the fact that the thread is responding to the bulk chloride concentration $(0.1 \mathrm{M} \mathrm{KCl})$ rather than the local concentration inherent to the $3 \mathrm{M}$ internal solution in the half cell.

It is clear that the silver thread could be used as a versatile reference-counter electrode with the silver deposit providing an extremely large surface area in comparison to the gold wire working electrode. The dependence on the chloride concentration within the sample could be an issue when considering the use of the thread within a sensing scenario where variations in the former could lead 
to ambiguities in ascribing peak positions. It is likely however that the homeostatic regulation of chloride within the tissues (typically $0.1 \mathrm{M}$ ) would reduce magnitude of any peak shift. It must be noted however that the drug release actuation proposed here employs large negative potentials that are unlikely to be influenced by minor shifts in the reference potential.

\section{Electrochemical release}

The electrode (suture) assembly was placed in a small volume cuvette and the potential held at various reducing potentials and the consequent release of the TBO into the solution monitored through uv-spectroscopic analysis. The resulting spectra for the application of the $-1.75 \mathrm{~V}$ are shown in Figure 4A with a quantitative analysis of the drug yield per 10s cycle shown in Figure 4B. The TBO absorption peak $(591 \mathrm{~nm}$ ) increases with each application of the reducing potential giving a relatively linear response in the initial phases with each 10 second cycle releasing about $2 \mu \mathrm{g}$ of the TBO. The latter will obviously be highly dependent on the processing of the suture (Figure 4B Inset) and the loading of the drug and, as expected, there is a fair degree of variability between runs given the preliminary nature of manufacture described here.

It is clear from Figure 4B that the release of the TBO can be achieved through the electrochemical control of the suture potential. The magnitude of the latter is necessarily large to effect a relatively quick dissolution of the polymeric binder but it can be expected that this could be attenuated through using less harsh negative potentials. The main criteria is that the potential is sufficient to evoke the hydrogen evolution[17]. In our experiments the application of -1V for example was found to be too slow to induce dissolution of the CAP release the TBO. Controlling the time through which the potential is applied is another option.

\subsection{Conclusions}

The core advantage of the system presented here lies in the ability to meter the dosing of the model drug through inducing a change in the local $\mathrm{pH}$. It must also be recognised that the latter only persists while the electrode potential is maintained and that the natural buffer components within of the matrix will quickly act to restore the $\mathrm{pH}$ to that of the bulk. In doing so, the release process is only momentary and will terminate upon removal of the reducing potential. There is however one caveat to the adoption of the technique in that it is important that the drug itself does not contain any reducible functionality (i.e. nitro groups) which may be inadvertently reduced whilst imposing the reducing potential. While more rigorous means of manufacture would improve the reproducibility of delivery, it is evident that the approach provides a versatile platform through 
which manipulation of either the magnitude of the potential or the duration over which it is applied can easily control the release process.

\section{Acknowledgements}

The authors thank the Department of Learning (DEL) Northern Ireland for supporting this work. 


\section{References}

1. C. Dennis, S. Sethu, S. Nayak, L. Mohan, Y.Morsi, G. Manivasagam. Suture materials - Current and emerging trends. J. Biomed. Mater. Res. Part A. 104 (2016) 1544-1559.

2. F.M. Alshomer, A. Madhavan, O. Pathan W.H. Song. Bioactive Sutures: A Review of the Advances in Surgical Sutures Functionalization.Suture review, Curr. Med. Chem., 24 (2017) 215-223

3. X. Wu, N.Z. Kubilay, J. Ren, B. Allegranzi, P. Bischoff, B. Zayed, D. Pittet, J. Li, Antimicrobial-coated sutures to decrease surgical site infections: a systematic review and meta-analysis, European J. Clin. Micro. \& Infect. Dis. 36 (2017) 19-32

4. J-M. Seitz, M. Durisin, J. Goldman, J.W. Drelich, Recent Advances in Biodegradable Metals for Medical Sutures: A Critical Review, Adv. Healthcare Mats. 4 (2015) 1915-1936

5. C.D. Owens, K. Stoessel. Surgical site infections : epidemiology, microbiology and prevention. J. Hosp. Infect. 70 (2008) 3-10.

6. G. De Angelis, A. Murthy, J. Beyersmann, S. Harbarth. Estimating the impact of healthcare-associated infections on length of stay and costs. Clin. Microbiol. Infect. 16 (2010) 1729-1735.

7. K. Yamashita, S. Takeno, S. Hoshino, H. Shiwaku, N. Aisu, Triclosan sutures for surgical site infection in colorectal cancer. J. Surg. Res. 206 (2016) 16-21

8. O. Catanzano, S. Acierno, P. Russo, M. Cervasio, M.D. De Caro, A. Bolognese, G. Sammartino, L. Califano, G. Marenzi, A. Calignano, D. Acierno, F. Quaglia. Melt-spun bioactive sutures containing nanohybrids for local delivery of anti-inflammatory drugs . Mater. Sci. Eng. C. 43 (2014) 300-309

9. S. Zhang, X. Liu, H. Wang, J. Peng, K.K.Y. Wong. Silver nanoparticle-coated suture effectively reduces inflammation and improves mechanical strength at intestinal anastomosis in mice. J. Pediatr. Surg. 49 (2014) 606-613.

10. A. L. Gallo, F. Paladini, A. Romano, T. Verri, A. Quattrini, A. Sannino. M. Pollini. Efficacy of silver coated surgical sutures on bacterial contamination, cellular response and wound healing. Mater. Sci. Eng. C. 69 (2016) 884-893

11. D. Kim, S. Wang, H. Keum, R. Ghaffari, Y. Kim, H. Tao, B. Panilaitis, M. Li, Z. Kang, F. Omenetto, Y.G. Huang, J.A. Rogers, Thin, Flexible Sensors and Actuators as "Instrumented " Surgical Sutures for Targeted Wound Monitoring and Therapy. Small, 8 (2012) 3263-3268.

12. K.P. Dasan, C. Rekha, Polymer Blend Microspheres for Controlled Drug Release: The Techniques for Preparation and Characterization: A Review Article, Curr. Drug Deliv. 9 (2012) 588-595

13. A. Bertz, S. Wohl-Bruhn, S. Miethe, B. Tiersch, J. Koetz, M. Hust, H. Bunjes, H. Menzel, Encapsulation of proteins in hydrogel carrier systems for controlled drug delivery: Influence of network structure and drug size on release rate, J. Biotechnol. 163 (2013) 243-249

14. C.Y. Wong, J. Martinez, R. Carnagarin, C.R. Dass, In-vitro evaluation of enteric coated insulin tablets containing absorption enhancer and enzyme inhibitor, J. Pharm. and Pharmacol., 69 (2017) 285-294 
15. A.Hanafi, N. Nograles, S. Abdullah, M.N. Shamsudin, R. Rosli, Cellulose acetate phthalate Microencapsulation and delivery of plasmid DNA to the intestines, J. Pharm. Sci., 102 (2013) 617-626

16. K.E. Kelley, S. Hernandez-Diaz, E.L. Chaplin, R. Hauser, A.A. Mitchell, Identification of Phthalates in Medications and Dietary Supplement Formulations in the United States and Canada, Env. Health Perspectives, 120 (2012) 379-384

17. A.Anderson, A. McConville, J.Davis, Electrochemical bubble rip: A new approach to controlled drug release, Electrochemistry Communications, 60 (2015) 88-91

18. R. Ashayer-Soltani, C. Hunt, O.Thomas. Fabrication of highly conductive stretchable textile with silver nanoparticles, Textile Research Journal, 86 (2016) 1041-1049

19. S. Liu, M. Hu, J. Yang, A facile way of fabricating a flexible and conductive cotton fabric, J. Mats. Chem. C. 4 (2016) $1320-1325$

20. H. Liu, L-L Zhu, Y. He, B.W. Cheng. A novel method for fabricating elastic conductive polyurethane filaments by in-situ reduction of polydopamine and electroless silver plating. Materials \& Design, 113 (2017) 254-263

21. C.C. Chu. Mechanical properties of suture materials: an important characterization. Ann. Surg, 193 (1981)365-371. 


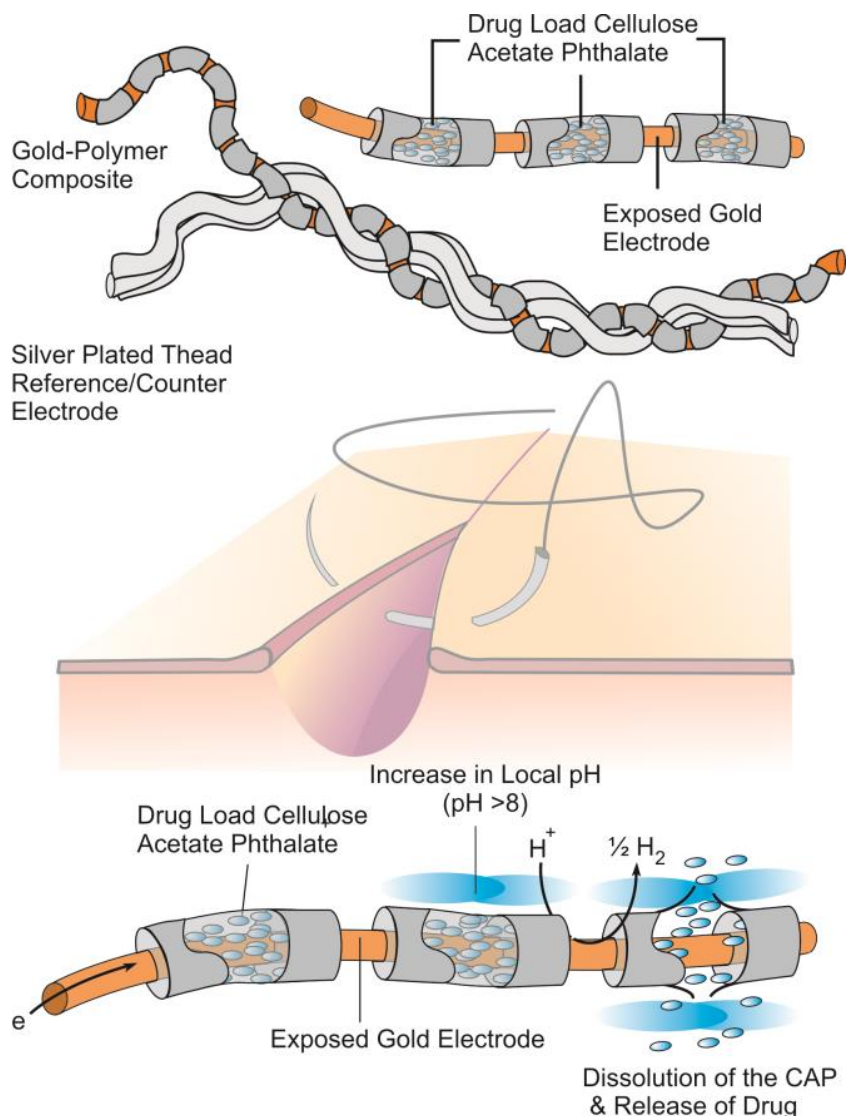

Figure 1. Proposed controlled release methodology 


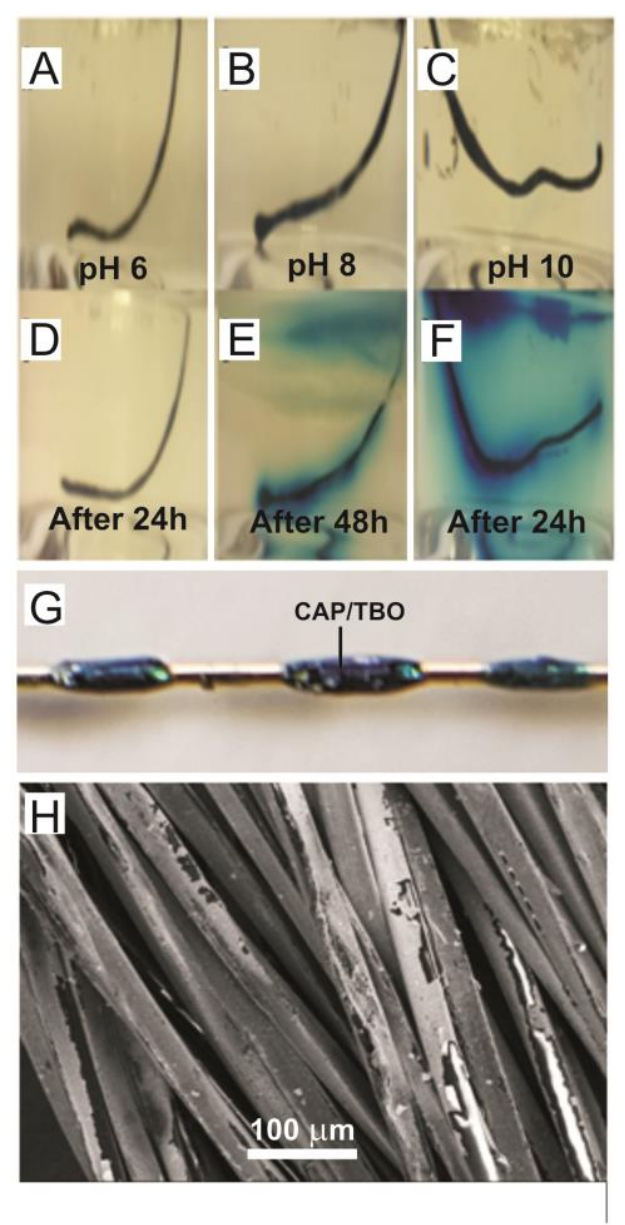

Figure 2. Release of Toluidine Blue $\mathrm{O}$ from Cellulose Acetate Polymer Coating on thread immersed in gelatin of varying $\mathrm{pH}$ (A-F). (G) Gold microwire $(100 \mu \mathrm{m})$ modified with CAP/TBO droplets. (H) Electron micrograph of the silver suture thread. 


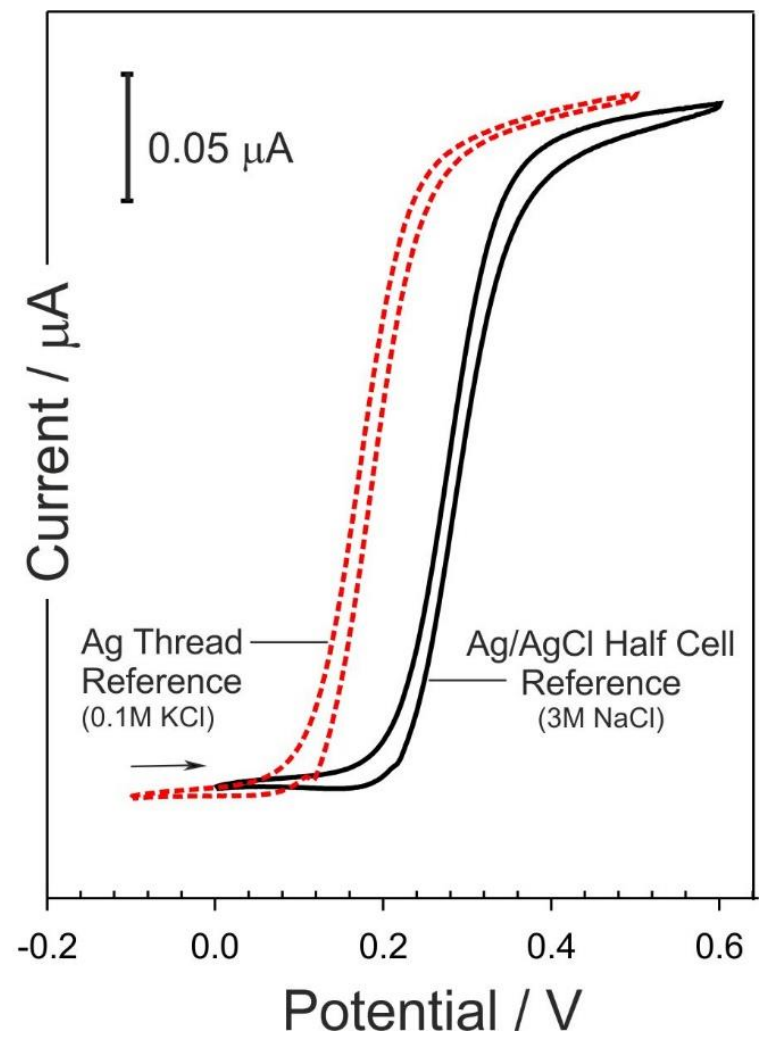

Figure 3. Cyclic voltammograms detailing the response of a gold wire $(50 \mu \mathrm{m})$ towards ferrocyanide ( $2 \mathrm{mM}, 0.1 \mathrm{M} \mathrm{KCl}, 5 \mathrm{mV} / \mathrm{s}$ ) using three electrode (solid line) and two electrode (dashed line) configurations. Silver thread was used as the combined reference-counter in the two electrode (prototype suture) investigation. 

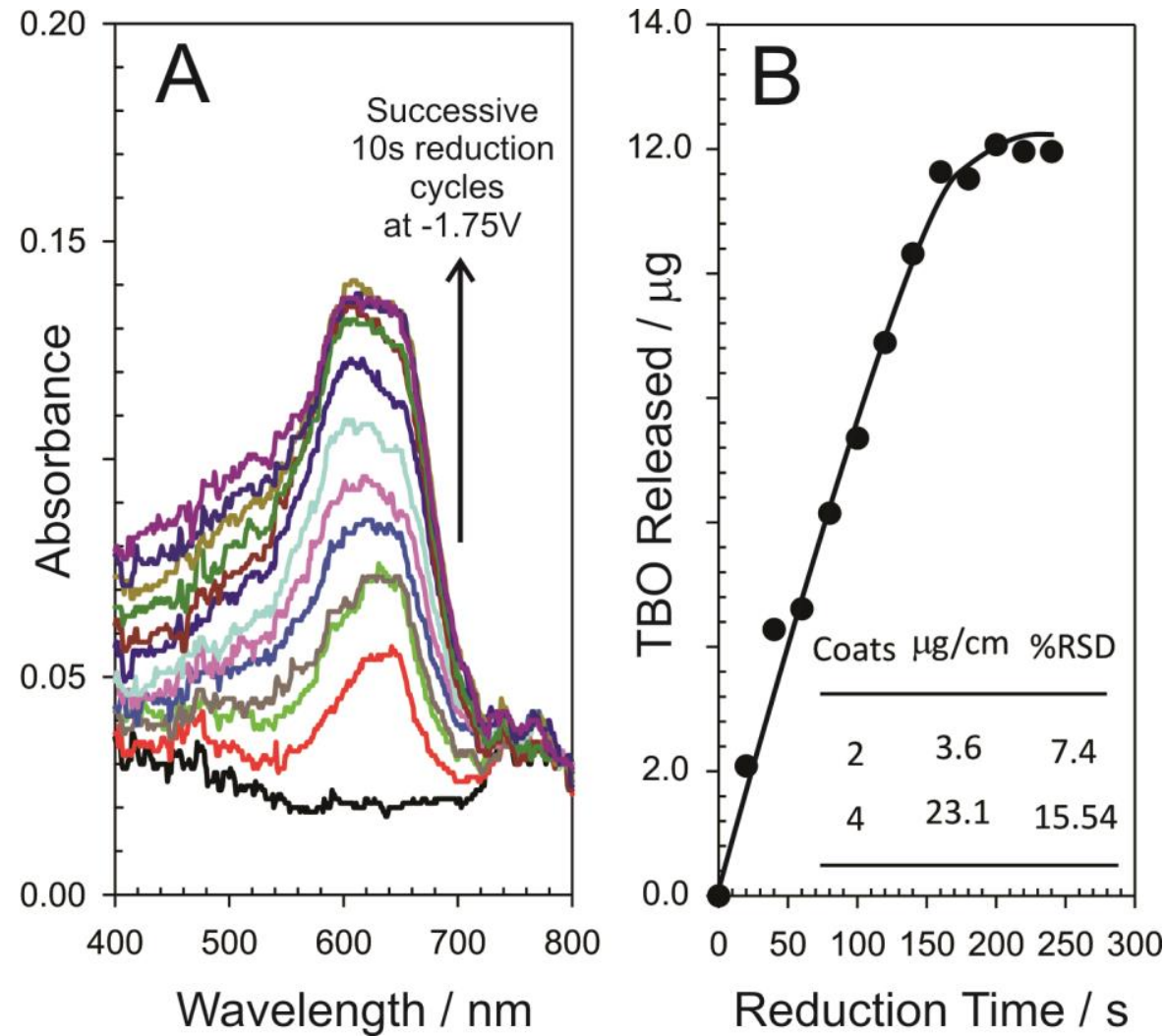

Figure 4. A) Spectra detailing the release of TBO after successive applications of a reducing potential (-1.75V for $10 \mathrm{~s}$ increments) from a $5 \mathrm{~cm}$ length of $100 \mu \mathrm{m}$ CAP coated gold wire. B) Yield of drug ( $\mu \mathrm{g})$ per $10 \mathrm{~s}$ reduction cycle. Inset: Typical yield per length of suture depending on coating. 